\title{
VLDL-C Oxidation
}

National Cancer Institute

\section{Source}

National Cancer Institute. VLDL-C Oxidation. NCI Thesaurus. Code C129900.

The presence of oxidized elements in cholesterol-bearing very low-density lipoprotein (VLDL) particles in the blood. Oxidation may be associated with increased risk for atherosclerosis. 